MAIA, C.A. et al. Anemia Infecciosa Eqüina - Revisão de literatura. PUBVET, Londrina, V. 5, N. 11, Ed. 158, Art. 1067, 2011.

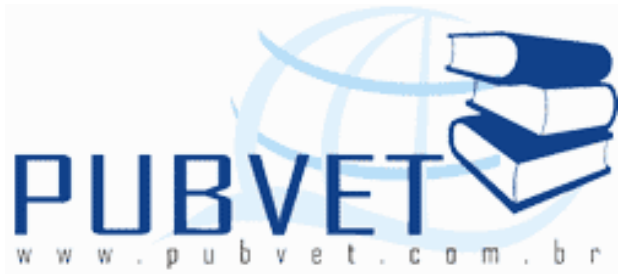

PUBVET, Publicações em Medicina Veterinária e Zootecnia.

\title{
Anemia Infecciosa Eqüina - Revisão de literatura
}

\section{Carolina Aparecida Maia ${ }^{1}$; César Augusto Garcia²; Daise Aparecida Rossi ${ }^{3}$;}

Roberta Torres de Melo ${ }^{4}$; Eliane Pereira Mendonça ${ }^{4}$; Letícia Rispoli Coelho ${ }^{4}$; Guilherme Paz Monteiro ${ }^{4}$; Priscila Christen Nalevaiko ${ }^{1}$

${ }^{1}$ Graduanda em Medicina Veterinária pela Universidade Federal de Uberlândia;

${ }^{2}$ Docente da Faculdade de Medicina Veterinária da Universidade Federal de Uberlândia; ${ }^{3}$ Docente do Programa de Pós Graduação da Universidade Federal de Uberlândia; ${ }^{4}$ Mestrandos do Programa de Pós Graduação da Universidade Federal de Uberlândia. Laboratório de Biotecnologia Animal Aplicada. Rua Ceará, Bloco 2D, Sala 43, Campus Umuarama, Uberlândia, MG.

\section{Resumo}

Os eqüídeos são ferramentas de trabalho essenciais à pecuária de corte, a qual é desenvolvida extensivamente no Brasil. A anemia infecciosa eqüina (AIE), conhecida mundialmente como febre-do-pântano, é considerada uma das principais doenças que acometem eqüídeos. É uma doença infecciosa, provocada por vírus, transmitida por meio do sangue de um animal infectado, picada de insetos hematófagos ou por agulhas, leite, placenta (transmissão congênita), sêmen (acasalamento) e pelo soro imune. A anemia não tem cura. Uma vez o animal infectado, torna-se portador permanente, podendo apresentar ou não os sinais da doença (forma aguda, crônica), constituindo-se numa fonte de infecção para outros eqüinos. O objetivo desse trabalho é 
MAIA, C.A. et al. Anemia Infecciosa Eqüina - Revisão de literatura. PUBVET, Londrina, V. 5, N. 11, Ed. 158, Art. 1067, 2011.

apresentar noções básicas sobre anemia, seus sintomas, causas e conseqüências.

Palavras-chave: Anemia Infecciosa, Eqüino, Vírus.

\title{
Equine Infectious Anemia - A Review
}

\begin{abstract}
The horses are essential tools for the extensive beef cattle raising, which is developed extensively in Brazil. Equine Infectious Anemia (EIA), known worldwide as the fever-swamp, is considered one of the major diseases that affect equines. It is a infected disease caused to virus, transmitted through of the blood of infected animal, hematophagous insect sting or needle, milk, placenta (congenital transmition), sperm (animal copulation) and for imune serum. Anemia has no cure. Once the infected animal, it becomes permanent carrier, which can make or signs of illness (acute, chronic), constituting a source of infection for other horses. The aim of this paper is to show about anemia, its symptoms, causes and consequences.
\end{abstract}

Keywords: Infectious Anemia, Equine, Virus.

\section{INTRODUÇÃO}

A Anemia Infeccisa Equina (AIE), também conhecida como Febre dos Pântanos ou "Swamp Fever", Malária Eqüina, AIDS do cavalo, Mal do Cochilo ou Cochilão é considerada uma das principais doenças infecto-contagiosas da equideocultura brasileira, para a qual não há vacina eficaz e tratamento (AIELLO et al., 2001).

A A.I.E. é causada por um vírus do gênero Lentivírus da família Retroviridae, que acomete cavalos, asininos e muares. A transmissão ocorre principalmente por insetos hematófagos do gênero Tabanidae (ISSEL e COGGINS, 1979; CLABOUGH, 1990; COOK et al., 2001).

Os estudos iniciais desta doença foram realizados na França, no século XIX e, atualmente, apresenta distribuição mundial. A AIE é uma infecção 
MAIA, C.A. et al. Anemia Infecciosa Eqüina - Revisão de literatura. PUBVET, Londrina, V. 5, N. 11, Ed. 158, Art. 1067, 2011.

persistente, resultando em episódios periódicos de febre, anemia, hemorragias, redução no número de glóbulos brancos e plaquetas com supressão transitória da resposta imunológica. Sinais clínicos como perda de peso, depressão, desorientação, andar em círculos e febre têm sido observados, no entanto, muitos animais portadores assintomáticos, não apresentam qualquer sinal clínico associado à AIE (SILVA et al., 2004).

A AIE é um entrave para o desenvolvimento da equideocultura, por ser uma doença transmissível e incurável, acarretando prejuízos aos proprietários que necessitam do trabalho desses animais e aos criadores interessados na melhoria das raças, além de impedir o acesso ao mercado nacional e internacional (ALMEIDA et al., 2006).

O diagnóstico laboratorial é de fundamental importância para detecção dos portadores da doença que, de acordo com a legislação (Instrução Normativa D.A.S. $n^{\circ}$. 16 , de 18 de fevereiro de 2004), devem ser sacrificados, promovendo o saneamento dos rebanhos (BRASIL, 2004). Em 1980, cientistas reconheceram a estreita relação entre o vírus da AIE e o Vírus da Síndrome da Imunodeficiência Adquirida Humana (AIDS). Isto levou a novas pesquisas sobre a patogenia da AIE, e novas descobertas sobre o vírus e a doença (TRAUB-DARGATZ, 1993).

\section{Etiologia}

O agente etiológico da AIE é o Vírus da Anemia Infecciosa Eqüina, oficialmente classificado na subfamília Lentivirinae, da família Retroviridae, baseado em sua estrutura, organização genética, atividade de transcriptase reversa e reatividade sorológica cruzada (FENNER et al., 1993; TRAUBDARGATZ, 1993). Relaciona-se intimamente com outros lentivírus, incluindo o vírus da Arterite Encefalite Caprina, o vírus Maedi/Visna dos ovinos e o vírus da Imunodeficiência Felina e Humana.

O vírus da AIE é um vírus do tipo RNA, envelopado, contendo um núcleo de forma cônica e densa. O envelope lipídico do vírus é derivado da membrana plasmática de células do hospedeiro durante a maturação da partícula. O vírus 
MAIA, C.A. et al. Anemia Infecciosa Eqüina - Revisão de literatura. PUBVET, Londrina, V. 5, N. 11, Ed. 158, Art. 1067, 2011.

da Anemia Infecciosa Eqüina apresenta duas glicoproteínas codificadas no envelope ( $\mathrm{gP} 90$ e gP 45) e de quatro proteínas não glicosiladas maiores ( $\mathrm{p} 26$, p15, p11 e p9). A p26 é a principal proteína do núcleo e demonstra especificidade do grupo, enquanto as glicoproteínas associadas ao envelope demonstram atividade de hemaglutinação e são específicas do tipo (HIRSH e ZEE, 2003). As glicoproteínas gP 90 e gP 45 são, provavelmente, exigidas para a penetração do vírus na célula hospedeira e atuam também como imunoestimulantes (TIMONEY et al., 1988).

As nucleoproteínas estruturais não glicosiladas são menos predispostas a variação antigênica do que as glicoproteínas de superfície. A mais abrangente proteína do núcleo, a p26, induz uma forte resposta imune humoral na maioria dos cavalos infectados, e é usada como base na maioria dos testes de diagnóstico sorológicos para o vírus (TRAUBDARGATZ, 1993). Segundo Hirsh e Zee (2003), o vírus da Anemia Infecciosa Equina é inativado em poucos minutos por desinfetantes comuns que contêm detergentes. O vírus também é inativado por hidróxido de sódio, hipoclorito de sódio, pela maioria dos solventes orgânicos e pela clorexidina. Quando aquecido a $56^{\circ} \mathrm{C}$ por 30 minutos, o vírus da AIE presente no soro eqüino não é infeccioso para outros eqüinos. Contudo, a $25^{\circ} \mathrm{C}$, ele permanece infeccioso por 96 horas em agulhas hipodérmicas.

O vírus da AIE é estável entre pH 6,0 e 9,0, mas é parcialmente inativado se incubado em $\mathrm{pH}$ menor que 5,0 . São inativados em $56^{\circ} \mathrm{C}$ por 30 minutos, mas podem apresentar maior resistência a irradiações e a luz ultravioleta devido a seu genoma diplóide (FENNER et al., 1993; MURPHY et al., 1999).

\section{Patogenia}

Imediatamente após a infecção, o vírus da AIE replica, primariamente em macrófagos maduros do tecido hepático, baço, nódulos linfáticos, pulmões, rins e glândulas adrenais. Vírions descendentes são liberados na circulação e títulos do vírus aparecem com o aumento paralelo da temperatura retal que 
MAIA, C.A. et al. Anemia Infecciosa Eqüina - Revisão de literatura. PUBVET, Londrina, V. 5, N. 11, Ed. 158, Art. 1067, 2011.

ocorre após o período de incubação de 7 a 21 dias (WEIBLEN, 2001).

Cavalos infectados são incapazes de remover completamente o vírus do seu organismo e permanecem infectados por toda a vida, apesar da montagem de uma forte resposta imune humoral e celular ao vírus da AIE. Muitos sinais clínicos e lesões tanto da doença crônica como na aguda são atribuídos a esta resposta imune do hospedeiro para o vírus e não um resultado direto da multiplicação viral (TIMONEY et al., 1988; FENNER et al., 1993; TRAUBDARGATZ, 1993; MURPHY et al., 1999).

Apesar de a variação antigênica ser um importante fator para a persistência viral, outros fatores também estão envolvidos. O fator mais importante que contribui para a persistência viral, provavelmente, é a habilidade do vírus em inserir uma cópia de DNA viral no DNA cromossomal do hospedeiro, formando o pro-vírus, que pode não ser manifestado por longo período de tempo, com pouca ou nenhuma transcrição ou tradução de genes virais. Se a célula não está expressando antígeno viral, ela não será reconhecida como infectada pelos métodos de vigilância imune do hospedeiro. O estímulo responsável pela reativação do pro-vírus ainda não é conhecido totalmente (TRAUB-DARGATZ, 1993), mas sabe-se que fatores imunosupressores como administração de corticóides, doenças que debilitem o sistema imunológico ou estresse, induzem a recrudescência da doença e o aparecimento de alguns sinais clínicos (KONO et al.,1976; TUMAS et al., 1994; CRAIGO et al., 2002).

A anemia que surge nessa enfermidade é causada principalmente pela destruição das hemácias, por meio de um mecanismo imunologicamente mediado. Estudos mais sensíveis pela eluição (separação de um sólido de outro por lavagem), têm demonstrado que a imunoglobulina está presente em pequenas quantidades na superfície dos eritrócitos dos cavalos com AIE (TRAUBDARGATZ, 1993).

Muito sobre a patogenia da Anemia Infecciosa Eqüina ainda não é compreendido. Contudo, em geral se admite que a anemia, glomerulonefrite, hepatite e a linfadenopatia resultam da deposição de imunocomplexos. Um dos 
MAIA, C.A. et al. Anemia Infecciosa Eqüina - Revisão de literatura. PUBVET, Londrina, V. 5, N. 11, Ed. 158, Art. 1067, 2011.

aspectos da doença que também é pouco compreendido é o fato de a complexidade da resposta imunológica do hospedeiro permitir a sobrevivência do vírus, ao mesmo tempo em que acarreta hipergamaglobulinemia (TRAUBDARGATZ,1993).

\section{Aspectos Clínicos}

As manifestações clínicas no animal infectado pelo vírus da AIE podem ser divididas em: aguda, crônica, inaparente ou assintomática. A forma aguda da doença é caracterizada por febre de 40,5 á $41^{\circ} \mathrm{C}$, anorexia e acentuada viremia. A forma crônica apresenta manifestações clínicas e anatomopatológicas que incluem perda de peso, edema, leucopenia, trombocitopenia resultando em hemorragias, letargia, glomerulonefrite e ataxia.

\section{Controle e Prevenção}

A Anemia Infecciosa Eqüina é uma moléstia sem tratamento específico. Como tentativa de conter a disseminação do vírus dentre a população de eqüídeos, têm sido objetivadas medidas de controle e prevenção.

O desenvolvimento de uma vacina eficaz contra infecções por lentivírus permanece sendo uma grande prioridade na medicina humana quanto na medicina veterinária (LEROUX e MONTELARO, 2004). Apesar dos esforços e realização de diversos experimentos e estudos nacionais e internacionais, não há atualmente vacina eficaz contra a AIE. Naturalmente e experimentalmente os animais infectados pelo vírus da AIE controlam com êxito a replicação viral e a doença dentro de poucos meses, tornando-se portadores assintomáticos.

No Brasil as medidas de controle e profilaxia à AIE seguem a Instrução Normativa da Secretaria de Defesa Agropecuária do Ministério da Agricultura, Pecuária e Abastecimento no 16, de 18 de Fevereiro de 2004. As normas devem ser tomadas de acordo com as condições epidemiológicas peculiares de cada Unidade de Federação, através das Comissões Estaduais de Prevenção e Controle da AIE (CECAIE). 
MAIA, C.A. et al. Anemia Infecciosa Eqüina - Revisão de literatura. PUBVET, Londrina, V. 5, N. 11, Ed. 158, Art. 1067, 2011.

Dentre as regras propostas pelo MAPA, para requisição do exame para diagnóstico da AIE utiliza-se o modelo oficial e para a identificação do animal é necessária uma descrição escrita e gráfica de todas as marcas, de forma completa e acurada. No levantamento sorológico de controle de propriedade, deve-se utilizar o formulário "Requisição e resultado para exame de Anemia Infecciosa Eqüina para fins de levantamento sorológico", o qual não possui validade para trânsito. A validade do resultado negativo para o exame laboratorial de AIE será de 180 dias para propriedade controlada e 60 dias para os demais casos, a contar da data da colheita da amostra.

Na propriedade que for detectado o foco de AIE, deverá ser adotado as seguintes medidas obrigatórias pelo MAPA:

- interdição da propriedade após identificação do eqüídeo portador, redigindo o termo de interdição, notificando o proprietário da proibição de trânsito dos eqüídeos da propriedade e da movimentação dos objetos passíveis de veiculação do vírus da AIE;

- deverá ser realizada investigação epidemiológica de todos os animais que reagiram ao teste de diagnóstico de AIE, incluindo histórico de trânsito;

- marcação permanente dos eqüídeos portadores da AIE, através da aplicação de ferro candente, na paleta do lado esquerdo com um " $\mathrm{A}$ ", contido em um círculo de 8 (oito) centímetros de diâmetro, seguido da sigla da UF, conforme modelo do MAPA;

- Sacrifício ou isolamento dos eqüídeos portadores;

- Realização de exame laboratorial, para o diagnóstico da AIE, de todos os eqüídeos existentes na propriedade;

- Desinterdição da propriedade foco após realização de 2 (dois) exames consecutivos com resultados negativos para AIE, e com intervalo de 30 (trinta) a 60 (sessenta) dias, nos eqüídeos existentes;

- Orientação aos proprietários das propriedades que se encontrarem na área perifocal, pelo serviço veterinário oficial, para que submetam seus animais a exames laboratoriais para diagnóstico de AIE. 
MAIA, C.A. et al. Anemia Infecciosa Eqüina - Revisão de literatura. PUBVET, Londrina, V. 5, N. 11, Ed. 158, Art. 1067, 2011.

O sacrifício ou o isolamento de eqüídeos portadores da AIE deverá ser determinado segundo as normas estabelecidas pelo Departamento de Defesa Animal, após análise das medidas propostas pelo CECAIE. Quando a medida indicada for o sacrifício do animal portador, esta só poderá ser feita após o reteste que é realizado em laboratório oficial, com amostra colhida pelo serviço oficial, para fins de perícia. É facultado ao proprietário do animal, requerer exame de contraprova. A contraprova deverá ser solicitada ao Serviço de Sanidade Animal - SSA, no prazo máximo de 8 dias contados a partir do recebimento da notificação do resultado, e será efetuada no mesmo laboratório que realizou o primeiro exame. Não há indenização ao proprietário do animal sacrificado (BRASIL, 2004).

Dentre as instruções para controle e prevenção da AIE pelo MAPA constitui-se propriedades controladas, quando não apresentarem reagentes positivos em duas provas sucessivas de IDGA à AIE, com intervalo de 30 e 60 dias e todo o seu rebanho eqüídeo deve ser submetido ao teste uma vez a cada 6 meses. Esse título pode ser renovado anualmente e será conferido certificado, mas essa deve encaminhar ao Serviço de Sanidade Animal (SSA) da respectiva UF um relatório mensal. O título de propriedade controlada é na realidade difícil, pois com a saída dos animais para as exposições, vaquejadas, folias, eventos diversos, estes animais estarão expostos à infeç̧ão, podendo permanecer alguns dias na propriedade "supostamente controlada" e sendo fonte de infecção aos outros animais que permaneceram no haras.

O trânsito interestadual no Brasil, somente será permitido mediante a apresentação do Guia de Trânsito Animal (GTA) e do resultado negativo no exame laboratorial para diagnóstico de AIE.

\section{Diagnóstico}

Durante muitos anos a ausência de animais de laboratório susceptíveis e de linhagens celulares que possibilitassem o crescimento e conseqüente estudo do vírus da $\mathrm{AIE}$, foram um grande entrave para o desenvolvimento de técnicas de diagnóstico. Até o final da década de 60 e início de década de 70, o 
MAIA, C.A. et al. Anemia Infecciosa Eqüina - Revisão de literatura. PUBVET, Londrina, V. 5, N. 11, Ed. 158, Art. 1067, 2011.

diagnóstico da AIE era feito com base na sintomatologia clínica, ainda que difícil, tanto no estágio agudo como no crônico da doença, na presença de sideroleucócitos provenientes da medula óssea em esfregaços sanguíneos e na histologia por hemossiderose linfonodal, hepática e hiperplasia do retículoendotélio (CORRÊA e CORRÊA, 1992). A identificação da doença transmitida dependia apenas dos achados clínicos (como sinais de febre recorrente, edema ventral e perda de peso), clínico patológicos (trombocitopenia, anemia, icterícia) e da necropsia (esplenomegalia e glomerulonefrite principalmente). Depois que Kobayashi e Kono (1967), conseguiram multiplicar o vírus da AIE em cultura de leucócitos e posteriormente adaptá-lo a linhagens celulares contínuas, vários testes sorológicos foram desenvolvidos.

Em 1970, o teste de Imunodifusão em Gel de Agar (IDGA) foi descrito constituindo um marco no diagnóstico da AIE, por ser de fácil execução, relativamente sensível e específico (COGGINS e NORCROSS, 1970). Foi o primeiro teste disponível comercialmente e o único prescrito oficialmente para trânsito pela Organização Mundial de Sanidade Animal, pelo Ministério da Agricultura, Pecuária e Abastecimento. Apesar disto, ele apresenta algumas limitações, dentre elas, a incapacidade de detectar anticorpos para o vírus da AIE nos estágios iniciais da doença. Esta prova recebeu a denominação de "Teste de Coggins". É qualitativa, isto é, identifica o animal portador e não portador, é reconhecida mundialmente como método laboratorial mais importante no diagnóstico da AIE, pela sua alta especificidade, devido ao fato de que a maioria das reações inespecíficas poderá ser identificada pela formação de linhas de "não identidade", facilidade de execução e alto grau de sensibilidade - em torno de 95\% (SELLON, 1993).

O antígeno escolhido na prova de imunodifusão é a proteína principal do core viral, a p26. Esta proteína mostrou ser altamente conservada em diferentes variantes isoladas, uma vez que o vírus sofre alta variação antigênica, resultando em mutantes com diferentes antígenos.

O teste da Imunodifusão em Gel de Agar (IDGA) é simples. Em uma placa ou lâmina contendo agar solidificado são feitas 7 cavidades ( 1 central e 6 
MAIA, C.A. et al. Anemia Infecciosa Eqüina - Revisão de literatura. PUBVET, Londrina, V. 5, N. 11, Ed. 158, Art. 1067, 2011.

circundando-a). Na cavidade central é colocado o antígeno (p26) enquanto nas demais alternam-se soro controle positivo e soro teste. Durante a incubação (48hs), ocorre a difusão do antígeno da cavidade central e de anticorpos se presentes, das cavidades externas. Se no soro teste existe anticorpos contra o antígeno p26, forma-se uma linha de precipitação no encontro desses anticorpos com a p26, que será contínua a linha formada entre o antígeno e o soro padrão positivo.

Em algumas situações, pode ser difícil determinar se o teste é negativo ou positivo. No caso de não haver anticorpos suficientes para a formação de uma linha visível, poderá ocorrer um resultado falso negativo. Este teste não consegue detectar animais positivos durante os primeiros 5 a 7 dias dos episódios clínicos, e este animal virá a dar um resultado positivo somente 15 a 25 dias após a inoculação do vírus (Vallée).

\section{Lâmina de IDGA para exame de A.I.E:}

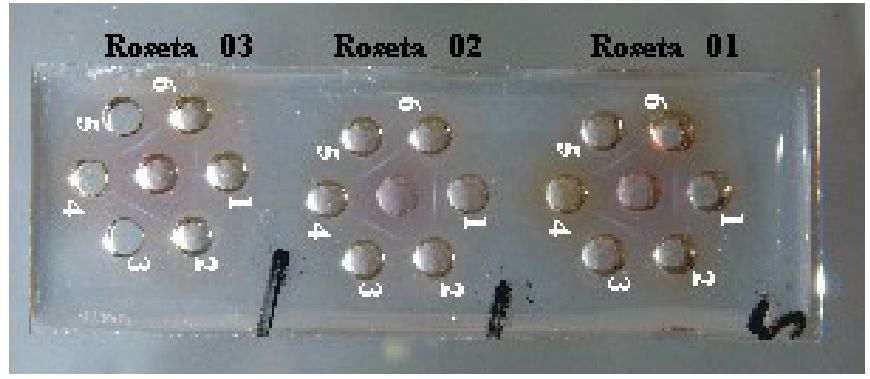

\section{Interpretação do Exame:}

\section{Legenda:}

1,3,5 - Soro Controle Positivo

2,4,6 - Soros de Animais em teste

\section{Resultado:}

Roseta 01 - Todos os animais testados $(2,4,6)$ são negativos.

Roseta 02 - Animal Posição 2 é positivo e animais posição 4 e 6 são negativos. Roseta 03 - Animal posição 4 é positivo (reação fraca) e animais posição 2 e 6 negativos. 
MAIA, C.A. et al. Anemia Infecciosa Eqüina - Revisão de literatura. PUBVET, Londrina, V. 5, N. 11, Ed. 158, Art. 1067, 2011.

Outros testes sorológicos foram desenvolvidos para o diagnóstico da AIE. Testes baseados na técnica de ELISA, detectando animais em estágios positivos mais precoces, em torno de 12 dias pós infecção (FERRAZ, 1998). O ELISA de competição (CELISA) que detecta também anticorpos contra o p26, o AS-ELISA, ELISA que utiliza um antígeno sintético e detecta anticorpos contra a gP45. ELISA, utilizando gP 90 recombinante, que detecta anticorpos para o vírus da AIE mais precocemente em animais infectados o qual apresenta boa correlação com os resultados do teste de IDGA e foi recomendado como teste de triagem em levantamentos sorológicos (MARTINS, 2004). Montelaro et al. (1984) demonstraram que os anticorpos específicos para a glicoproteína gP 90 da superfície viral são 100 a 1000 vezes mais abundantes do que os anticorpos específicos para p26, sendo também os primeiros a serem detectados no sangue.

\section{Diagnóstico diferencial}

Enfermidades como a Arterite Viral Eqüina e a Babesiose constituem importante diagnóstico diferencial de AIE. O diagnóstico pode ser realizado por observação histopatológica das lesões características, Isolamento Viral, Inoculação em Cultivo Celular, PCR, ELISA, Soro-Neutralização, Fixação do Complemento (TIMONEY et al., 1988). O diagnóstico da Babesiose deve ser realizado pelo esfregaço de sangue periférico com visualização de protozoários no interior dos eritrócitos, por Fixação do Complemento e de anticorpos fluorescentes indiretos (SMITH, 1993).

\section{Coleta e remessa ao laboratório:}

- Validade do exame: 60 dias da data da coleta da amostra.

- Coleta da amostra: deve ser colhida por médico veterinário inscrito no conselho regional da respectiva UF. Este veterinário deve:

1 - Fazer coleta do material para realizar exame (utilizando uma agulha para cada animal);

2 - Preencher a requisição em modelo oficial (fornecida pelo laboratório 
MAIA, C.A. et al. Anemia Infecciosa Eqüina - Revisão de literatura. PUBVET, Londrina, V. 5, N. 11, Ed. 158, Art. 1067, 2011.

credenciado) sendo necessária para a identificação do animal uma descrição escrita e gráfica de todas as marcas de forma completa e acurada. A responsabilidade legal pela veracidade e fidelidade das informações prestadas na requisição é do médico veterinário requisitante, portanto é de suma importância o veterinário coletar a(s) amostra(s), identificá-la(s) e preencher $a(s)$ requisição(ões) de forma completa e permitindo a identificação do animal e a propriedade onde ele se encontra. $O$ termo de compromisso também deve ser todo preenchido e assinado.

- Procedimentos para recepção de amostras:

O laboratório só pode receber o material e dar início ao exame com a amostra (SORO NÃO HEMOLISADO) e requisição preenchida por completo, assinada e com carimbo do médico veterinário (nas 3 vias da requisição).

As amostras devem ser enviadas em caixas isotérmicas sob conservação em gelo.

\section{REFERÊNCIAS BIBLIOGRÁFICAS}

AIELLO, B.S.S.E., D.V.M., E.L.S. Manual Merck de Veterinária. 8 ed. São Paulo: Editora Roca LTDA. 2001. 1861p.

ALMEIDA, V.M.A., et al. Anemia infecciosa eqüina: prevalência em eqüídeos de serviço em Minas Gerais. Arq. Bras. Med. Vet. Zootec, v.58, n.2, p.141-148, 2006.

BRASIL. Instrução Normativa da Secretaria de Defesa Agropecuária do Ministério da Agricultura, Pecuária e Abastecimento número 16, de 18 de Fevereiro de 2004.

CLABOUGH, D.L. The immunopathogenesis and control of equine infectious anemia. Vet. Med., v.85, p.1020-1027, 1990.

COGGINS, L.; NORCROSS, N.L. Immuno-diffusion reaction in equine infectious anemia. Cornell Vet.,v.60, p.330-335, 1970.

COOK, S.J., et al. Differencial responses of Equus caballus and Equus asinus to infection with two pathogenic strains of equine infectious anemia virus. Vet Microbiol., v.79, p.93-109, 2001.

CORRÊA, W.M.; CORRÊA, C.N.M. Enfermidades infecciosas dos mamíferos domésticos, MEDSI, Rio de Janeiro, p.695-698, 1992.

CRAIGO, J.K., et al. Transient immune suppression of inapparent carriers infected with a principal neutralizing domain-deficient equine infectious anemia virus induces neutralizing antibodies and lowers steady-state virus replication, J. Gen. Virol. 83. p1353-1359. 2002

FENNER, F.J., et al. Veterinary Virology. $2^{a}$ ed. Academic Press, Inc. San Diego, p.666, 1993. 
MAIA, C.A. et al. Anemia Infecciosa Eqüina - Revisão de literatura. PUBVET, Londrina, V. 5, N. 11, Ed. 158, Art. 1067, 2011.

FERRAZ, I.B.F., et al. Detection of infectious anemia viral DNA (provirus) in pheripheral blood cells and ELISA test of one experimental infected horse. Virus Reviews e Research, v.2, n. 1-2, p.198-199, 1997.

HIRSH, D.C.; ZEE, Y.C. Microbiologia Veterinária. $2^{\mathrm{a} e d . G u a n a b a r a ~ K o o g a n ~ S . A . ~ R i o ~ d e ~}$ Janeiro. p.424-425, 2003.

ISSEL, C.J., et al. A perspective on equine infectious anemia with emphasis on vector transmission and genetic analysis. Vet. Micro., v.17, p.251-286,1988.

ISSEL, C.J.; COGGINS, L. Equine infectious anemia: current knowledge. J. Am. Vet. Med. Assoc., v.174, p.727-733, 1979.

KONO, Y., et al. Recrudescence of equine infectious anemia by treatment with immunosuppressive drugs, Natl. Inst. Anim. Health Q. Tókio v.16, p. 8 -15, 1976.

LEROUX, C., Cadoré Jean-Luc, MONTELARO, R. C. Equine Infectious Anemia Vírus (EIAV): what has HIV's country cousin got to tell us? Vet. Res. 35; p.485- 512; 2004.

MURPHY F.A., et al. Veterinary Virology. 3 rd Academic Press, Inc. San Diego. 1999. 629p.

SILVA, R.A.M.S., et al. Programa de Prevenção e Controle da Anemia Infecciosa Eqüina no Pantanal Sul-Matogrossense. Documentos 68. Corumbá Embrapa Pantanal, p.9-10, 2004

SELLON, D.C. Equine infectious anemia. Vet. Clin. N. Am: Equine Pract. v.9, p.321-336, 1993.

$\mathrm{SMITH}, \mathrm{B}$. P. Tratado de medicina veterinária interna de grandes animais: moléstia de eqüinos, bovinos, ovinos e caprinos. Editora: Manole LTDA 1. ed. São Paulo: Editora : Manole LTDA Volume 2, $1993.1738 \mathrm{p}$.

TIMONEY, J.F.; GILLESPIE, J.H.; SCOTT, F.W. Hagan and Bruner's Microbiology and Infectious Diseases of Domestic Animals. 8 ed. Cornell University Press. Ithaca. 1988. 951 p.

TRAUB-DARGATZ, D.C. Equine Infectious Anemia. In: Sellon, D.C. The Veterinary Clinics of North America- Equine Practice. 1ed. W.B. Saunders Company Philadelphia, p.321-336. 1993.

TUMAS, D.B., et al. Corticosteroid immunosuppression and monoclonal antibodymediated CD5+ T lymphocyte depletion in normal and equine infectious anaemia virus-carrier horses, J.Gen. Virol.75. p.959-968. 1994.

WEIBLEN, R. Doenças Víricas. Anemia Infecciosa Eqüina. IN: RIET-CORREA F.; SCHILD, A.L.; MENDEZ, M.D.C.; LEMOS, R.A. Doenças de Ruminantes e eqüinos. 2 ed. São Paulo: Editora Varela. Vol.1, p.49-55, 2001. 